\title{
The Bahaman Hutia: a Rodent Refound
}

\author{
By Garrett C. Clough
}

In 1966, on a small rocky uninhabited island in the Bahamas, the author discovered an abundant population of the Bahaman hutia, a nocturnal rodent the size of a rabbit, which had been reported extinct. In three visits to the islands he has studied the hutias, now strictly protected by the Bahaman government, and is also breeding them in captivity both for study and as a safety precaution - one catastrophe such as an exceptional hurricane could wipe out the whole population. The author is Assistant Professor of Zoology at Rhode Island University.

\begin{abstract}
A
RELIC population of the Bahaman hutia, a small rodent, listed as extinct in some recent books, has been rediscovered on a tiny island in the Bahamas, and many new details of its ecology and habits learned. Even the few people who were aware of its continued existence knew almost nothing about its biology and numbers. In 1966, I found a thriving population of Geocapromys ingrahami living in an interesting ecological situation on East Plana Cay, and at the University of Rhode Island I now have a small colony of captive animals breeding successfully. The following observations are the result of three week-long visits to this island from 1966 to 1968.
\end{abstract}

East Plana Cay is a coral-rock island of 1100 acres ( 465 hectares) near the south-east end of the Bahaman archipelago $\left(22^{\circ} 23^{\prime}, 73^{\circ} 30^{\prime}\right)$. The vegetation is semi-arid, with sparse shrub thickets and scattered cactus on the thin sandy soil and limestone terraces. The only fresh water found was one very temporary rain puddle in March 1966 during the first trip. The island is undermined with a labyrinth of caves and fissures, and loose slabs and chunks of the weathered coral rock form additional crevices and hollows. Its inhospitable nature has kept people away and has, I believe, saved this last surviving population of the species from extinction. On nearby islands humans and their domestic animals have apparently helped exterminate them, for hutia skeletal remains have been found together with food items of the early Indian inhabitants, and on the major islands of the Greater Antilles related genera of the capromyid family have been hunted and eaten until they are reported quite rare wherever they still occur.

The Bahaman hutia's strictly nocturnal habits have also allowed it to elude the occasional passing scientist stepping ashore on East Plana Cay for a few daylight hours. But half an hour after sunset the island becomes alive with these rabbit-sized rodents as they emerge from their underground hiding places - I estimated a total population of between 6000 and 12,000, a figure derived from repeated counts of animals on a measured area. On the basis of the similarity of a series of fecal pellet counts on square-meter sample plots on the census area and in other parts of the island, I discovered that the animals were evenly distributed over the 
island, at an estimated density of 12 animals per acre (30 per hectare). The average body weight of 98 animals was 715 grams. The resultant biomass is 19 pounds per acre ( 21.45 kilograms per hectare) which is remarkably high for the mammal population of such a semi-arid community. The population density was high during each of my visits - March 1966, October 1967 and March 1968. It is interesting that the original discoverer, D. P. Ingraham, who went ashore on East Plana Cay in 1891, also found them very abundant. There are no predators on this abundant herbivore, and no other mammals on the island except bats. The only large meateating birds were ospreys, which feed on fish exclusively. Only one other terrestrial vertebrate was abundant, the round-tailed lizard Leiocephalus greenwayi, which was active in the daytime, and we collected two other lizard species.

The plant-animal community of Plana Cay is limited, and we were able to collect only 30 species of plants, of which only six or eight were eaten by the hutias. Their food consisted of leaves, bark and entire small twigs of woody shrubs. They were adept at climbing a few feet up into the shrubs to reach the outer branches. They could run and jump rapidly up the short steep cliffs along the shore, but could be overtaken if pursued on the open beach away from the rocks. We captured over 100 by locating them with a strong flashlight and then running them down in the open with a hand net. Most of these were weighed, tagged with a small ear tag and released.

\section{A Mild Animal}

In the wild the hutias displayed a mild nature despite the crowded conditions which brought about almost constant social contact. The greatest hostility I saw was when a chase ended in a short rolling scuffle as one animal overtook another. Usually encounters were of a mild nature where two animals approached each other slowly and then parted with no overt aggression. On a number of occasions a very small hutia was seen moving close to an adult. Once when we captured one of these young animals of 175 grams weight we found that its loud distress calls attracted adults in the area. As we looked up from examining the baby we could see eight adults moving towards us from all directions. Low aggression may be a behavioral adaptation which permits the population to remain at high levels. Olfactory communication by extensive marking with urine plays some role in maintaining the hutia social order.

Calculations based on the food intake of captive animals and estimates of the annual productivity of the vegetation from other semi-arid habitats indicate that the hutias were at, or close to, the maximum capacity of their environment. Low reproduction evenly balanced with mortality would be necessary to keep the population below a disastrous level. A comparison of the descriptions given from Ingraham's visit, those of some later visits in the 1930s, and my own observations of the vegetation indicate that the rodent effect on the plant life has been fairly constant over the past 100 years. The plant-herbivore balance appears to have reached stability. The five records of reproduction we have are all of one young per litter. The related genera of Cuba and the other large Caribbean islands often 
have two per litter while the only mainland member of this family, the nutria or coypu, may have up to nine young at one time. Diseased individuals were quite common on Plana Cay; on our last visit 15 per cent of the animals we saw were visibly sick with fur in poor condition, considerably underweight or with diseased eyes.

The Bahaman Ministry of Agriculture and Fisheries has declared the entire island a protected area and now controls the study and collection of the hutia. After my initial trip with its encouraging estimate of numbers, I was granted permission to take up to 20 live animals off the island, which, after a few initial losses, have been living quite well in captivity; three of the four young born have survived. Our colony of 15 animals is now the subject of a social behaviour study, especially the role of urine marking as a social signal and means of influencing social organisation. Three animals were sent to Dr M. L. Johnson, of the University of Puget Sound, working with the Tacoma Zoological Society in Washington, and they have had one successful birth there. A pair was given last spring to the New York Zoological Society.

The future of the species seems assured as long as East Plana Cay remains undisturbed. But the animals remain susceptible both to natural catastrophe, such as an exceptional hurricane which could flood the entire low-lying island, or to exploitation by a rapidly increasing and proteinhungry people. To safeguard the species the Bahaman Ministry of Agriculture and Fisheries has approved a plan to transport a few dozen hutias from East Plana Cay to another uninhabited rocky island, which could be done without undue effort. This would also provide excellent scientific opportunities to learn about the hutias' impact on the food supply, and on the important general questions of the relation of growth, reproduction, mortality and social behaviour to population density.

\section{Vicuña Trade Continues}

$\mathbf{T}$

HE vicuña is completely protected in Argentina, but, as the secretary of the

Asociacion Natura says, "the best legislation will not achieve our goals ... mere prohibitions are easily flouted by poachers'. Argentina and Bolivia have signed a document agreeing measures on the future management of the vicuña. Meanwhile the trade continues and advertisements of vicuna wool fabrics imported into Argentina from England appear in all Buenos Aires newspapers. The log jam is still in Peru, where a new decree is still awaited that would enable action to be taken in England.

\section{Gambia's First Nature Reserve}

\footnotetext{
THE Abuko Nature Reserve - the Gambia's first - has been established only a dozen miles from the capital, Bathurst, in a small area (153 acres) that has been more or less undisturbed since 1912 when it was set aside as a waterworks gathering ground. It has good examples of the riverine forest and Guinea savanna zones, and an artificial lake boasts some impressive crocodiles - up to 16 feet. The problem is fencing: the original fence, temporarily patched up, is inadequate for the larger wildlife which it is hoped to introduce to make this a valuable educational reserve and also the tourist attraction, which it already shows signs of being, and an application has been made to WWF for assistance.
} 



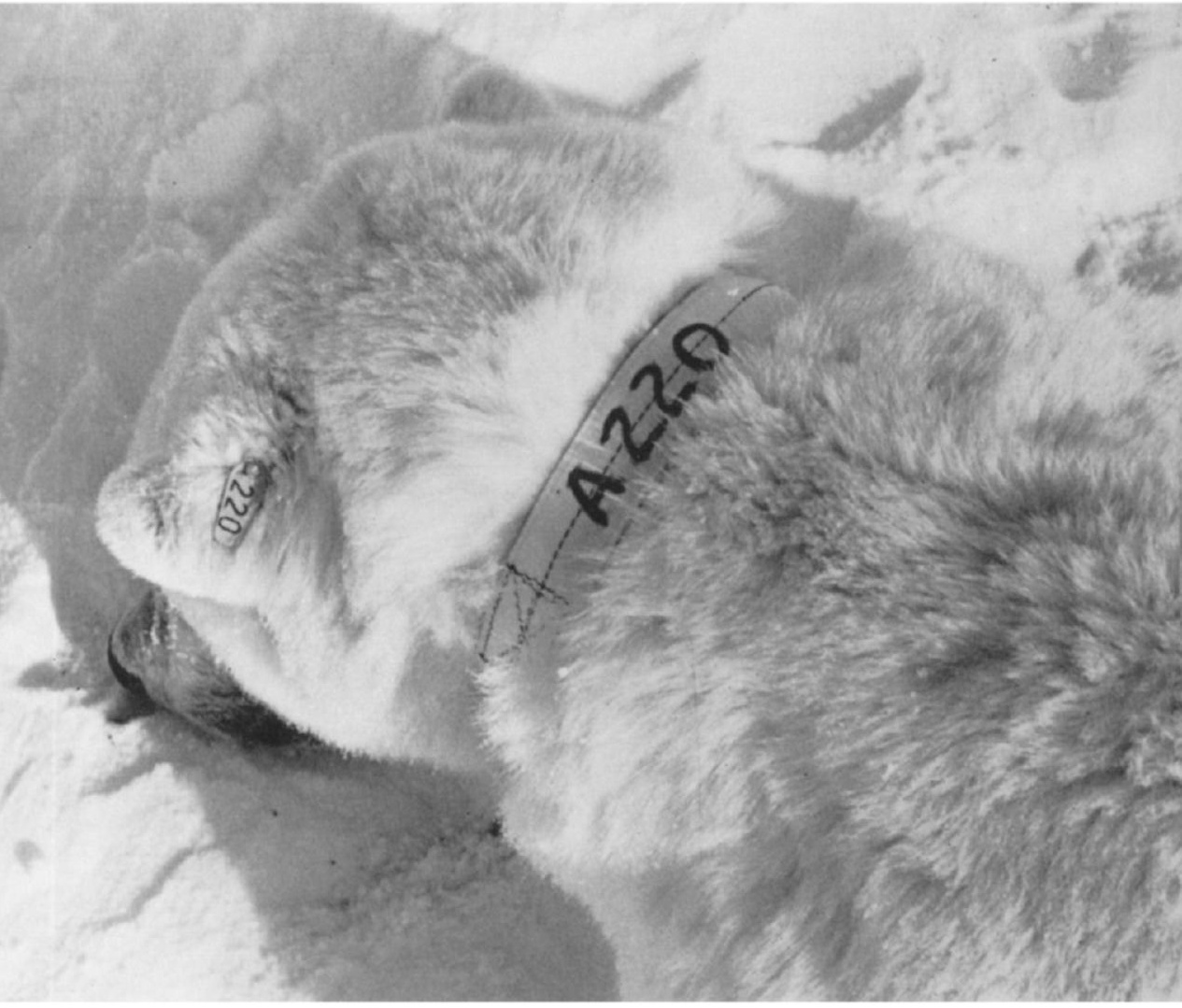

Plates 8 \& 9

Above, the identifying nylon collar and nylon ear-tag in place. Below, bear No 34 , recovered from the drug, makes a quick getaway. 


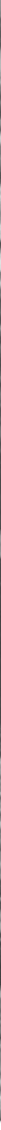

Plate 10

BONGO IN CAPTIVITY. Alan Root 